\title{
Consultation on indemnity cover for dentists and staff
}

The government has launched a consultation on the regulation of clinical negligence indemnity cover for healthcare professionals who buy their own indemnity cover because they are not covered by existing or proposed state-backed schemes, such as primary care dentists.

The consultation, launched on 6 December 2018, applies mostly to regulated professionals in the NHS who hold indemnity cover which is not currently regulated, such as primary care dentistry; private practice of medical doctors and other regulated healthcare professionals; and healthcare professionals in Northern Ireland and Scotland not covered by any state-backed indemnity scheme.

The government is seeking views on whether it should leave arrangements as they are or change legislation to require healthcare professionals who are not covered by any state-backed scheme to hold cover that is regulated.

It is concerned that under the present arrangements, healthcare professionals not covered by state-backed schemes could prevent patients getting appropriate compensation for negligence and put healthcare professionals at risk of being personally liable for the costs of claims.

This is because these arrangements are mostly discretionary, where the providers are not contractually obliged to meet the costs of any claim and are not subject to prudential or financial conduct regulation.

However, the overall cost of indemnity cover could increase as a result of the proposed changes, says the consultation document, because the government is seeking to impose a cost increase on health professionals by moving to an insurance based model that will attract a $12 \%$ insurance premium tax.

The document says: 'There are potential difficulties arising from a move to a regulated product. In the transition, current providers may be unable to, or choose not to, continue to provide cover and there could be higher overall costs of clinical negligence cover.'

Chief Executive of MDDUS, Chris Kenny, said: 'Instead of supporting choice and proposing concrete actions on legal reform that would make a real difference, the Government is seeking to impose a cost increase on health professionals by moving to an insurance based model that will attract a $12 \%$ insurance premium tax.

'Patients will not be better protected - the document acknowledges that there is no evidence of harm in the UK from the current discretionary model. Doctors and dentists will gain no benefit. The only winner is the Treasury with its additional $12 \%$ premium tax income.

'In short, there is little evidence to support the proposals, nor indeed that there is a real problem to be resolved other than increasing competition and transparency.'

Raj Rattan, Dental Director at Dental Protection, said: 'We are working with the Government on their proposal to regulate professional indemnity, contributing our knowledge and experience to ensure that members' needs remain at the forefront of any decisions made.

'We are already exploring the best way to offer members an insurance product. So, should the Government decide all dentists and doctors need to hold a regulated policy of insurance for clinical negligence risks, we are confident we will be in a strong position to offer this as a benefit of membership to UK members.'

The consultation closes on 28 February 2019.

1. Dept of Health and Social Care. Appropriate clinical negligence cover. 2018. Available at https://www.gov.uk/government/consultations/appropriate-clinical-negligence-cover?utm_source $=e 95 f 02 c b-8 c a 9-4 c 46-9 e a 9-d 8 e 83 b 6 a 1 a 82 \& u t m \_m e d i u m=e m a i l \& u t m$ campaign=govuk-notifications\&utm_content=immediate (accessed December 2018)

\section{HPV catch-up programme off the cards}

The government appears to have decided not to implement a catch-up programme to protect up to two million boys still in school from the human papillomavirus (HPV), according to the BDA.

The union along with experts in the field had called on the government to offer HPV vaccination to boys aged up to 18 as a catch-up programme. This would run alongside the vaccination programme for 12/13-year-old boys which the government intends to rollout from September 2019.

However, in a letter sent to shadow health minister Sharon Hodgson (and seen by the $B D J$ ), public health minister Steve Brine said there would be no such catch-up programme for boys because older boys already benefited from 'herd protection' meaning they got indirect protection because of the earlier vaccination introduction for girls.

The letter said: 'Including a catch-up programme would place additional pressure on NHS delivery services, which risks delay or disruption to the roll-out of the routine HPV programme for boys or to other vaccination programmes.

'The additional benefits that a catch-up programme would afford to the routine one would be very small.'

Currently, girls in England are offered free HPV jabs at school during Years 8 and 9, when they are aged between 12 and 14. The latest Public Health England (PHE) data shows $83.8 \%$ of girls were given the recommended two doses of the vaccine by the end of Year 9 in 2017-18 - less than what is required for herd immunity - with nearly 50,000 $(48,545)$ girls missing out.

Peter Baker, Campaign Director for HPV Action, said: 'The JCVI [Joint Committee on Vaccination and Immunisation] took five long years to decide that boys should be vaccinated, three years more than originally planned.

'Because of the delay, over one million boys missed out on vaccinations and therefore remain at risk of the potentially life-threatening diseases caused by HPV, including oral cancers. A catch-up programme for boys still at school could reach around two million boys in total. When Australia introduced HPV vaccination for boys in 2013, it had a catch-up and UK boys surely deserve the same.'

The BDA said it had been a leading advocate for expanding the programme to boys because HPV was a leading cause of oral cancers.

Mick Armstrong, BDA Chair, said: 'The latest data on vaccinations among girls illustrates precisely why we've needed a genderneutral approach. It also shows why penny pinching on a catch-up programme will leave many school-aged boys unprotected.

"There can be no guarantees of "herd protection" when nearly 1 in 5 girls are missing out on the vaccine. A catch-up programme remains the best way to protect all our children.' 